\title{
Orthodontic treatment-related risks and complications: part I dental complications
}

\author{
Tiro, Alisa * \\ * Department of Orthodontics, School of Dental Medicine, University of Sarajevo, Bosnia and Herzegovina
}

\begin{abstract}
Introduction: Orthodontic treatment is a complex medical intervention carried out over an extended period. During this time, risks may turn into complications. It is necessary to identify the risks that are associated with the orthodontic intervention to be applied, as there are numerous complications possibly linked to that treatment. The occurrence of these complications depends on the orthodontic technique, medical knowledge in this field, patient's general and oral health, and oral hygiene habits. These must be considered even from the start because it might influence the treatment objectives, phases, and goals.

Aim: of this study is to present a contemporary attitude of the main risks and complications linked to orthodontic interventions in clinical practice.

Materials and methods: Classification presented by Graber et al. in publication, "Risk management in orthodontics: expert's guide to malpractice," is used as a starting point for the development of this review. A complex search was performed (Pubmed, Google scholar, etc.), with the restriction upon of publication date (beginning with 2004) to find relevant current studies. Search keywords were combinations of words: complication, orthodontic treatment, risks, side effects.

Concluding remarks: According to contemporary literature, there are a lot of conditions to which orthodontic treatment can be linked There is a medico-legal obligation to inform our patients about side effects of any medical intervention what will be undertaken.
\end{abstract}

Tiro A. Orthodontic Treatment-Related Risks and Complications: part I dental complications. South Eur J Orthod Dentofac Res. 2017;4(2):43-47.

Submitted: March 23, 2017; Revised: July 27, 2017; Published: September 22, 2017

\section{INTRODUCTION}

The benefits of a medical intervention must outweigh any potential harm. Apart from its benefits, orthodontic treatment can cause certain complications. During clinical orthodontic procedures, the use of various methods, devices, and materials can cause unwanted side effects, both local (e.g., tooth discoloration, decalcification, root resorption, and periodontal complications) and systemic (e.g., allergic reactions and crossinfections). The legislation governing medical behavior requires that each patient undergoing treatment must be informed of the benefits and risks of the treatment. If side effects occur and a patient has not been properly informed about the risks

\section{Corresponding Author:}

Tiro Alisa

Department of Orthodontics,

School of Dental Medicine,

University of Sarajevo,

Bolnička 4a, Sarajevo 7100, BiH and possible complications of the treatment, the result can be complaints of abuse or even lawsuits. It is recommended that each patient makes a serious analysis of the risks and potential complications of treatment, which can be followed by signed informed consent. ${ }^{1}$

According to numerous authors, there are a lot of conditions to which orthodontic treatment can be linked. Even if there are no proofs of direct cause/effect relationships for most of them, we must still consider them seriously and inform our patients about them. The possible risks and complications associated with orthodontic treatment, according to their effects, can be divided into two main groups: the risks and complications of systemic effects and the risks and complications of local effects. $^{2,3}$

Risks and complications of orthodontic procedures with local effect are:

Dental complications

Potential complications on the crown level during orthodontic 
interventionare: decalcifications, decay, toothwear, enamelcracks and fractures, discolorations, damage to the prosthetic crown(s), such as fracturing of a ceramic crown during debonding. 4,5 On the root level, there may appear to be root resorption, early closure of root apex, or ankylosis. ${ }^{6-8}$ Pulpal complications during orthodontic procedures can be ischemia, pulpitis, or even necrosis. ${ }^{9-12}$

\section{Periodontal complications}

Periodontal complications that may appear during orthodontic treatment are gingivitis, periodontitis, gingival recession or hypertrophy, alveolar bone loss, dehiscences, fenestrations, interdental folds, and dark triangles. ${ }^{13-15}$

\section{Soft tissue alterations}

Soft tissue alterations are a common side effect of orthodontic treatment. It can be seen as a laceration of the gingiva or oral mucosa, chemical burns (etching related), thermal injuries (overheated burs), or stomatitis. In some cases, more serious problems like ulceration or tissue hyperplasia around the bracket, end of wire or loop, may appear. The most serious injuries are those of the face or neck. ${ }^{16,17}$

\section{Temporomandibular joint (TMJ) disorders}

TMJ disorders condylar resorption, temporomandibular dysfunction. ${ }^{18,19}$

\section{Unsatisfactory treatment outcomes}

Unsatisfactory treatment outcomes are inadequate morphofunctional, aesthetic or functional final result, relapse, failure to complete treatment course, incorrect diagnosis, incorrect management. ${ }^{16,20,21}$

\section{BACKGROUND}

The classification was presented by Graber et al. (2004) in the publication Risk management in orthodontics: experts' guide to malpractice and was used as a starting point for the development of this study. A complex search was performed (Pubmed, google scholar, etc.), with the restriction upon of publication date (beginning with 2004) to find relevant current studies. Search keywords were combinations of words: complications, orthodontic treatment, risk, systemic, local, and side effects.

This part will discuss dental complications.

\section{Dental complications}

\section{Enamel damages}

Bonding of orthodontic appliances may induce irreversible changes of a tooth surface. The enamel changes depend on numerous factors: the acid type and concentration, time of application, and enamel surface characteristics. The most severe modifications appear when conventional resins are used as bonding materials. The self-etching adhesive resin bonding technique is safer and better than conventional resins which separate the phase of etching. This technique produces less enamel damage but has the disadvantages of lower bond strength. Also, resin-modified glass ionomer cement is preferred as a bonding material. This bonding material reduces enamel damage thanks to fluor releasing, and it has a bond strength similar to resins. ${ }^{22-25}$ The debonding and removal phase of orthodontic treatment may cause tooth damage as enamel loss or cracks. The frequency of enamel loss depends on the brackets, bonding materials, and debonding technique. Enamel damage is usually less with metallic braces and bonding materials, depending on if glass ionomer cement is used. Using ceramic brackets and conventional adhesive resins and bonding materials cause more severe enamel modification. The proper debonding technique is to break the link between bracket and adhesive. The presence of horizontal enamel cracks after debonding are associated directly with the orthodontic technique. A high frequency of the vertical enamel cracks is present in the population without previous orthodontic treatment. ${ }^{26-29}$

\section{Caries}

Recent studies of this unwanted side effect show white spot prevalence of $70 \%, 5 \%$ cavity prevalence, and more than $30 \%$ of the maxillary incisors' decalcification after fixed orthodontic treatment. ${ }^{4,30,31}$ Demineralisation around brackets occurs as a result of improper oral hygiene. In orthodontic patients, the plaque index is higher compared with patients without orthodontic treatment. Evidence shows a decrease of salivary $\mathrm{pH}$ during orthodontic treatment. It is also observed an increased level of two main caries favoring factors such as Streptococcus mutans and Lactobacillus. ${ }^{14,32-34}$ It is mandatory to evaluate carioactivity and oral hygiene habits before starting orthodontic therapy. In some situations, a high frequency of dental caries and poor oral hygiene may be reasons to postpone or even cancel the orthodontic treatment. It is recommended that primary prevention methods be used to avoid this complication (i.e., educate patients about proper oral hygiene and diet), together with fluoride-releasing materials for brackets, bands or tubes. In some cases, a secondary prevention method is recommended: fluorination. Studies have shown that a daily fluoride mouth rinse or a fluoride-containing cement reduces tooth decay during treatment with fixed orthodontic appliances. ${ }^{35,36}$ When white spot lesions are present at the end of treatment, we can wait for spontaneous remineralization, and the chewing of sugar-free gums is recommended to improve salivation. ${ }^{37,38}$ The other options are the use of fluorine- or casein phosphopeptidebased products (tooth mousse) or performing microabrasion of the front teeth's labial surfaces. ${ }^{38}$ 


\section{Color alterations}

Color alterations after orthodontic treatment are the result of several factors. More severe alterations occur when chemicallycured resins are used as bonding materials rather than lightcured composites. ${ }^{22,39}$

The resin tags cannot be removed by cleaning procedures without altering the enamel's surface. Irreversible changes occur to the enamel's surface morphology, rugosity, and texture, with negative consequences on its reflective properties, luminosity, and optical perception. Evidence shows that the adhesive resins used for bracket bonding do not present good color stability with time. Ultraviolet light and corrosion products from the orthodontic appliance combined with food dyes induce color alterations, with a tendency to move toward the yellow tones. ${ }^{29,40}$ Orthodontic forces induce variations in pulp vascularization. It is a possible factor for the premature aging of teeth, and it is an endogenous factor for discoloration too. ${ }^{9-11}$ In situations where white spots and lesions are present, even if remineralization occurs, the outcome may be different from the initial enamel structure. This is because of the differences in the minerals in the treated enamel surface compared to the untreated enamel. ${ }^{4,5,22}$

\section{Enamel abrasion}

The tooth wear (enamel abrasion) is another dental alteration which may occur in the orthodontic patients caused by contact between the teeth and brackets or tubes. A higher frequency of this was noticed in the patients with ceramic brackets compared to the patients with metallic brackets. ${ }^{2,21,29,41}$

\section{External apical root resorption}

External apical root resorption is an unavoidable consequence of orthodontic treatment. The etiology is multifactorial: individual biologic characteristics, genetic predisposition and the effect of orthodontic forces. ${ }^{6}$ Studies based on microscopic analysis show a prevalence of $100 \%$ after the orthodontic treatment. ${ }^{42}$ Apical root resorption occurs in different degrees. A Severe level is defined as a tooth shortening more than $4 \mathrm{~mm}$ or one-third of the root length. The root shortening more than $2 \mathrm{~mm}$ is present in $5-18 \%$ of cases, and more than $4 \mathrm{~mm}$ or $1 / 3$ of tooth length in $1-5 \%$ of the cases. ${ }^{43,44}$ Risk factors for apical tooth resorption can be present as patient characteristics-related and orthodontic technique-related. Patient-related factors include genetics, general health factors, the type of malocclusion, tooth-root morphology, a previous history of root resorption, alveolar bone density, root proximity to cortical bone, endodontic treatment, and patient age and sex. One of the genetic factors in root resorption presence is polymorphism of the IL-1beta gene. ${ }^{45,46}$ Apical tooth resorption is different between ethnic groups. Asians show a less frequency of root resorption compared to Caucasians or Hispanics. ${ }^{44}$ The severe tooth resorption is more frequently associated with health conditions such as allergies, asthma, diabetes, arthritis and endocrine disorders. ${ }^{1}$ Apical root resorption is associated with an abnormal direction of tooth eruption (pressure of the third molar may induce tooth resorption of the second molar, or tooth resorption of lateral incisor or bicuspid because of canine pressure). Among the patients with different malocclusions, there is a different amount of tooth resorption. ${ }^{47}$ The skeletal open bite is more frequently associated with apical root resorption than malocclusion without hyperdivergent facial patterns. During the years before treatment starts, the frontal teeth do not participate in an occlusion. The periodontal tissues of those teeth are insufficient for submitting the orthodontic forces during treatment. Patients with Angle Class II or III malocclusion present more severe apical root resorption than those with Class I malocclusion.

Among Class I malocclusion patients, those with therapeutic tooth extraction are more at risk of apical root resorption. ${ }^{48}$ Root morphology is one of the most important factors linked to apical root resorption. Teeth with long, narrow roots; abnormal root shapes in the apical parts' or curved, eroded, peaked, or barrelshaped roots are marked as high-risk ones. The next important factor is tooth topography. Maxillary teeth are more susceptible to root resorption compared to mandibular ones. The frontal teeth havea bigger chancefor root resorption than the posterior teeth. ${ }^{49,50}$ Orthodontic treatment-related risk factors include treatment duration, the magnitude of applied force, the direction of tooth movement, the amount of apical displacement, the type of force application, and the method of force application. ${ }^{51,52}$ Treatment duration is one of the most important factors directly linked to apical root resorption. The optimal period of treatment duration is less than 18 months to prevent severe root resorption. ${ }^{8,53}$ The tooth's direction of movement may cause an increased risk of root resorption and tooth intrusion. The type of force application is an extremely important factor. Continuous and heavy forces during orthodontic tooth movement are linked with apical root resorption. ${ }^{54}$ When the patient with a high risk of root resorption is identified, it is recommended to avoid teeth extractions, if it is possible, to avoid heavy and continuous forces, disjunction, and long treatment duration. Also, it is necessary to check root resorption signs, analyzing the periapical space on the radiograph six months after orthodontic treatment was started. ${ }^{42,44,55}$

\section{CONCLUDING REMARKS}

There is a medico-legal obligation to inform our patients about side effects of any medical intervention what will be undertaken. The orthodontic procedures of any dental-medical treatment should provide maximum benefit with minimal side effects. To ensure safer medical care, orthodontic treatment, as a part of dental-medical science, must be performed with great precaution. 


\section{REFERENCES}

1. Graber T, Eliades T, Athanasiou AE. Risk Management in Orthodontics: Experts Guide to Malpractice, 2004. Quintessence Publishing Co, Inc, Chicago.

2. Lau PY. Wong RWK. Risks and complications in orthodontic treatment. Hong Kong Dental Journal, 2006;3(1):15-22.

3. Ackerman M. Evidence-based orthodontics for the 21st century. J Am Dent Assoc. 2004;135(2):162-7

4. Al Maaitah EF, Adeyemi AA, Higham SM, Pender N, Harrison JE. Factors affecting demineralization during orthodontic treatment: a post-hoc analysis of RCT recruits. Am J Orthod Dentofacial Orthop. 2011;139(2):181-91

5. Danesh G, Hellak A, Lippold C, Ziebura T, Schafer E. Enamel surfaces following interproximal reduction with different methods. Angle Orthod. 2007;77(6):1004-10.

6. Motokawa M, Sasamoto T, Kaku M, Kawata T, Matsuda Y, Terao A, Tanne K. Association between root resorption incident to orthodontic treatment and treatment factors. Eur J Orthod, 2012; 34(3):350-6.

7. Ponder SN, Benavides E, Kapila S, Hatch NE. Quantification of external root resorption by low- vs high-resolution cone-beam computed tomography and periapical radiography: A volumetric and linear analysis. Am J Orthod Dentofacial Orthop. 2013;143(1):77-91.

8. Apajalahti S, Peltola JS. Apical root resorption after orthodontic treatment - a retrospective study. Eur J Orthod. 2007 Aug;29(4):408-12.

9. Santamaria M Jr, Milagres D, Stuani AS, Stuani MB, Ruellas AC. Initial changes in pulpal microvasculature during orthodontic tooth movement: a stereological study. Eur J Orthod 2006; 28(3):217-20.

10. Yamaguchi M, Kasai K. The Effects of Orthodontic Mechanics on the Dental Pulp. Seminars Orthod. 2007;13:272-80.

11. Ramazanzadeh BA, Sahhafian AA, Mohtasham N, Hassanzadeh N, Jahanbin A, Shakeri MT. Histological changes in human dental pulp following application of intrusive and extrusive orthodontic forces. J Oral Sci. 2009;51(1):109-15.

12. Sikorska-Bochińska J, Jamroszczyk K, Łagocka R, Lipski M, Nowicka A. Dentinal hypersensivity after vertical stripping of enamel. Ann Acad Med Stetin. 2009;55(2):65-7. Polish.

13. Dannan A. An update on periodontic-orthodontic interrelationships. J Indian Soc Periodontol. 2010;14(1):66-71.

14. Klukowska M, Bader A, Erbe C, Bellamy P, White DJ, Anastasia MK, Wehrbein H. Plaque levels of patients with fixed orthodontic appliances measured by digital plaque image analysis. Am J Orthod Dentofacial Orthop. 2011;139(5):e463-70.

15. Thilander B, Rygh P, Reitan K. Tissue reactions in orthodontics. in Orthodontics: Current Principles and Techniques, T. Graber, et al. eds., 2005. St Louis. Mosby; p.145-219.

16. Meeran NA. Iatrogenic possibilities of orthodontic treatment and modalities of prevention. J Orthod Sci. 2013;2(3):73-86.

17. Kerosuo HM, Dahl JE. Adverse patient reactions during orthodontic treatment with fixed appliances. Am J Orthod Dentofacial Orthop. 2007;132(6):789-95.

18. Mohlin B, Axelsson S, Paulin G, Pietilä T, Bondemark L, Brattström $\mathrm{V}$, Hansen $\mathrm{K}$, Holm AK. TMD in relation to malocclusion and orthodontic treatment. Angle Orthod. 2007;77(3):542-8.

19. Michelotti A, Iodice G. The role of orthodontics in temporomandibular disorders. J Oral Rehabil. 2010;37(6):411-29.
20. Daniels AS, Seacat JD, Inglehart MR. Orthodontic treatment motivation and cooperation: a cross-sectional analysis of adolescent patients' and parents' responses. Am J Orthod Dentofacial Orthop. 2009;136(6):780-7.7.

21. Shah AA, Sandler J. Limiting factors in orthodontic treatment: 1. Factors related to patient, operator and orthodontic appliances. Dent Update. 2006;33(1):43-4, 46-8, 51-2.

22. Fjeld M, Øgaard B. Scanning electron microscopic evaluation of enamel surfaces exposed to 3 orthodontic bonding systems. Am J Orthod Dentofacial Orthop. 2006;130(5):575-81.

23. Pessan JP, Al-Ibrahim NS, Buzalaf MA, Toumba KJ. Slow-release fluoride devices: a literature review. J Appl Oral Sci. 2008;16(4):238-46.

24. Vahid-Dastjerdi E, Borzabadi-Farahani A, Pourmofidi-Neistanak H, Amini N. An in-vitro assessment of weekly cumulative fluoride release from three glass ionomer cements used for orthodontic banding. Prog Orthod. 2012;13(1):49-56.

25. Lill DJ, Lindauer SJ, Tüfekçi E, Shroff B. Importance of pumice prophylaxis for bonding with self-etch primer. Am J Orthod Dentofacial Orthop. 2008;133(3):423-6.

26. Hosein I, Sherriff M, Ireland AJ. Enamel loss during bonding, debonding, and cleanup with use of a self-etching primer. Am J Orthod Dentofacial Orthop. 2004;126(6):717-24.

27. Naini FB, Gill DS. Tooth fracture associated with debonding a metal orthodontic bracket: a case report. World J Orthod. 2008;9(3):e32-6.

28. Eslamian L, Borzabadi-Farahani A, Mousavi N, Ghasemi A. A comparative study of shear bond strength between metal and ceramic brackets and artificially aged composite restorations using different surface treatments. Eur J Orthod. 2012;34(5):610-7.

29. Øgaard B, Fjeld M. The Enamel Surface and Bonding in Orthodontics. Seminars in Orthodontics. 2010;16(1):37- 48.

30. Chapman JA, Roberts WE, Eckert GJ, Kula KS, González-Cabezas C. Risk factors for incidence and severity of white spot lesions during treatment with fixed orthodontic appliances. Am J Orthod Dentofacial Orthop. 2010;138(2):188-94.

31. Shungin D, Olsson AI, Persson M. Orthodontic treatment-related white spot lesions: a 14-year prospective quantitative follow-up, including bonding material assessment. Am J Orthod Dentofacial Orthop. 2010;138(2):136.e1-8;

32. Srivastava K, Tikku T, Khanna R, Sachan K. Risk factors and management of white spot lesions in orthodontics. J Orthod Sci. 2013;2(2):43-9.

33. Vizitiu TC, Ionescu E. Microbiological changes in orthodontically treated patients. Therapeutics. Pharmacology and Clinical Toxicology. 2010;14(4):283-6.

34. Nakaš E, Džemidžić V, Tiro A, Pasić E, Hadžić S. Antimicrobial activity of chlorhexidine in patients with fixed orthodontic appliances. Braz J Oral Sci. 2011;10(2):79-82.

35. Ionescu E, Teodorescu E, Badarau A, Grigore R, Popa M. Prevention perspective in orthodontics and dento-facial orthopedics. J Med Life. 2008;1(4):397-402.

36. Delbem AC, Brighenti FL, Vieira AE, Cury JA. In vitro comparison of the cariostatic effect between topical application of fluoride gels and fluoride toothpaste. J Appl Oral Sci. 2004;12(2):121-6.

37. Burt BA. The use of sorbitol- and xylitol-sweetened chewing gum in caries control. J Am Dent Assoc. 2006;137(2):190-6. Erratum in: J Am Dent Assoc. 2006;137(4):447.

38. Bergstrand F, Twetman S. A review on prevention and treatment of post-orthodontic white spot lesions - evidence-based methods and emerging technologies. Open Dent J. 2011;5:158-62. 